\title{
MIREILLE CALLE-GRUBER, Pascal Quignard ou Les leçons de ténèbres de la littérature
}

\section{Stefano Genetti}

\section{OpenEdition}

\section{Journals}

\section{Edizione digitale}

URL: https://journals.openedition.org/studifrancesi/32298

DOI: 10.4000/studifrancesi.32298

ISSN: 2427-5856

\section{Editore}

Rosenberg \& Sellier

\section{Edizione cartacea}

Data di pubblicazione: 1 août 2020

Paginazione: 442-443

ISSN: 0039-2944

\section{Notizia bibliografica digitale}

Stefano Genetti, «mireille calle-gruber, Pascal Quignard ou Les leçons de ténèbres de la littérature», Studi Francesi [Online], 191 (LXIV | II) | 2020, online dal 01 septembre 2020, consultato il 18 septembre 2021. URL: http://journals.openedition.org/studifrancesi/32298; DOI: https://doi.org/10.4000/studifrancesi. 32298

Questo documento è stato generato automaticamente il 18 septembre 2021.

\section{(c) (i) (9)}

Studi Francesi è distribuita con Licenza Creative Commons Attribuzione - Non commerciale - Non opere derivate 4.0 Internazionale. 


\title{
MIREILLE CALLE-GRUBER, Pascal Quignard ou Les leçons de ténèbres de la littérature
}

\author{
Stefano Genetti
}

\section{NOTIZIA}

MIREILLE CALLE-GRUBER, Pascal Quignard ou Les leçons de ténèbres de la littérature, Paris,

Galilée, 2018, 194 pp.

1 Ad alcuni dei sei saggi, apparsi tra il 2005 e il 2017, estesi, rielaborati e qui riuniti, si è già avuto modo di accennare in queste pagine. Gli argomenti affrontati vanno dall'apocrifo come modalità di scrittura visionaria e ribelle a ogni definizione - in merito a $L a$ frontière e alle Tablettes de buis d'Apronenia Avitia - alla metamorfosi come chiave leggendaria per accedere, senza disvelarlo, al segreto della physis e dell'animalità umana, in merito alle Solidarités mystérieuses. Accostando temi quali il trauma della nascita, le rovine della Storia inscritte nell'infanzia e la creazione come erranza solitaria, etimologicamente sauvage (solus + vagus), come predazione e come estasi, l'A. mobilita testi poco commentati quali gli Écrits de l'éphémère o Requiem. Tornando sulle "lezioni" di Louis-René des Forêts e Emmanuel Hocquard assimilate da Pascal Quignard, raccorda tra loro traités e romanzi moltiplicando i nessi tra i primi scritti dell'autore e i più recenti. Nel montaggio scucito, allucinato, di biografemi, aforismi e altri «alogoï» (p. 14), nella riesumazione di figure appartate e testi ermetici della tradizione quali l'Alessandra di Licofrone e nella traduzione come interrogazione della fonte volta ad esaltarne «le sens multiple décalé et l'imprononçable» (p. 139), si rinvengono alcuni tratti di una scrittura che rivendica la contraddizione e la reticenza, «l'intraitable», «l'inconditionnel», «l'ab-solu» (p. 185).

2 Tra i contrari che in Quignard «ne s'opposent pas, ils s'appellent» (p. 19), a guidare l'immersione nell'opera, conferendo alla raccolta l'unità messa in rilievo nell'inedito 
primo capitolo («Nyctalope est la littérature», pp. 9-43), è la tensione di luce e tenebre, la propensione a cogliere l'attimo, la naissance du jour, l'eruzione estemporanea dell'originario, e ad accogliere il buio, il mistero, a evocare il perduto: la notte cosmica - il Caos primordiale, l'Ouvert di Le manuscrit sur l'air - e la notte infernale, terrestre; la scena invisibile del concepimento e la notte uterina, acquatica. «L'écrivain nyctalope fait l'éloge de l'ombre, montre l'obscur de l'obscur de la langue, où logent silence, mutisme, magnétisme, prémonition, l'inaudible et l'inapparaissant, qui ne sont pas le contraire du Dit mais les mesures de son immensurabilité» (p. 15). La prossimità con la manière noire dell'incisione di una scrittura imagée concepita come deposito di visioni oniriche, anche quando i caratteri non emergono dallo sfondo nero della pagina, come avviene in La nuit sexuelle, è la manifestazione di una pervasiva «poétique de la nyctalopie» (p. 67): la frase trema, tesa, e la pagina si apre come «l'œil écarquillé dans l'obscur» (p. 13). Negli ultimi anni, tale poetica culmina nelle performances de ténèbres che, tra luci e ombre, suoni e silenzio, al confluire di parola, musica e danza, vedono l'autore solo sul palco o in collaborazione con altri artisti. Su di esse Mireille CalleGruber ripetutamente si sofferma, anche in termini drammaturgici, attenti alla riattivazione del rituale sacrificale del dramma antico, alla lentezza del gesto che «déréalise» lo spazio (p. 24), alla presenza degli uccelli rapaci, nonché in relazione ai testi che le performances condensano - Villa Amalia nel récit-récital Femme disant adieu (2012), ad esempio - o cui preludono, come nel caso di Les ruines de Port-Royal (2014), ripreso in Sur l'idée d'une communauté de solitaires. In esse l'A. scorge «l'ultime et minimal avatar de l'écriture littéraire, à la limite de son évanouissement, échappée au manceps du logos et de l'écrivain lequel, cherchant à se désidentifier et se dépersonner [...], fonce dans la nuit où il prend la couleur de son encre» (p. 25).

Sul bord de scène delle performances de ténèbres, sulla riva tra due mondi, dove si intesse il dialogo con le ombre, si dispongono le cinque portes lettrées che formano il capitolo di chiusura «Les ténèbres pour speculum / Spéculer dans le noir» (pp. 175-190). Accompagnate da cinque scene immaginarie, sono altrettante risposte della spettatricescrittrice al «Comédien sauvage» (p. 189), al suo "performer l'obscur» (p. 14) liberandosi dell'io e trovando nel vuoto l'unico autentico «point d'attache» (P. QUIGNARD, La vie n'est pas une biographie, Paris, Galilée, 2019, p. 28), trasformando il «manque» in «surcroît» (p. 117) e facendo della «bouche d'ombre» «l'âme du texte» (p. 42). Al perdre pied e al lâcher prise ricercati, a tastoni, dallo scrittore in scena, alla teatralità notturna e nuda della performance, corrisponde un gesto critico consapevole «de toucher ses limites» (p. 41): equidistante dall'identificazione e dall'esplicazione, la lettura si vuole «chambre d'échos où abriter l'habitation des œuvres» (p. 43). Collocando Quignard «dans la lignée des écrivains contemplatifs» (p. 11), M. CalleGruber pratica una speculazione contemplativa in sintonia con la meditazione letteraria perseguita dall'autore: «c'est la philosophie qui n'aurait pas peur du noir, ni de la ruine des significations [...] et qui trouverait révélation au défaut des langues» (p. 151). Ad occhi sbarrati nel buio, «il ne s'agit pas de parler $d u$ silence mais de tendre l'ouïe (dire oui) à l'imprononçable. L'invisible» (p. 141): si tratta di perlustrare, senza gettarvi la luce cruda di un sapere, le zone d'ombra di una letteratura nyctalope che stimola «l'écoute suraiguë», poiché «elle ne fait pas entendre ce qu'on n'entend pas: elle fait entendre qu'on n'entend pas» (p. 16). 